\title{
The feasibility of a Two-incision video-assisted thoracoscopic lobectomy
}

\author{
Hyun Koo Kim", Ho Kyung Sung, Hyun Joo Lee and Young Ho Choi
}

\begin{abstract}
Background: This study is to evaluate the feasibility and safety of video-assisted thoracoscopic (VATS) lobectomy with two incisions.

Methods: A total of 73 patients (male 47, female 26; mean age $61.2 \pm 12.00$ years old) who underwent major pulmonary resection, through VATS, using two incisions were included in this study. The thoracoscopy port was placed at the 7th or the 8th intercostal space in the mid-axillary line, and the working port, $3 \sim 5 \mathrm{~cm}$ long, at the 5th intercostal space, on the operator's side.

Results: The preoperative diagnosis was benign lung disease in 8 patients (11.0\%) and malignant lung disease in 65 (89.0\%). Two patients (3.1\%) needed a third port during surgery due to severe pleural adhesion, and conversion to thoracotomy was needed in $5(6.8 \%)$, due to bleeding at pulmonary arterial branch $(n=3)$, anthracofibrotic lymph nodes around pulmonary artery $(n=1)$, and severe pleural adhesion $(n=1)$. The mean duration of the operation in the 66 patients, completed by a two-incision VATS lobectomy, was $163.4 \pm 30.40$ minutes. In 56 cases, which were completed by a two-incision VATS lobectomy for primary lung cancer, a total number of dissected lymph nodes per patient were $20.2 \pm 11.2$. The chest tube was removed on postoperative day $5.4 \pm 2.8$, and there was no occurrence of major perioperative morbidity and mortality.
\end{abstract}

Conclusions: Two-incision VATS lobectomy is applicable in the selected cases, and may obtain similar results with the conventional VATS lobectomy, through a certain period of learning curve.

Keywords: ThoracosocopyNATS, Lobectomy

\section{Background}

Since the first video-assisted thoracic surgery (VATS) lobectomy, with anatomic hilar dissection performed in 1992, the frequency of this procedure has increased due to its attractiveness as a minimally invasive modality, which results in fewer postoperative complications, and reduces the duration of pleural drainage, as well as a reduction in the length of the hospital stay [1-5]. However, the use of VATS lobectomy to perform anatomic lung resection for lung cancer remains controversial because there have been questions whether it reduces local disease recurrence and its positive effects of longterm survival [6,7]. Although a recent meta-analysis of randomized and nonrandomized trials demonstrated that VATS lobectomy is an appropriate procedure for selected

\footnotetext{
* Correspondence: kimhyunkoo@korea.ac.kr

Departments of Thoracic and Cardiovascular Surgery, Korea University Guro

Hospital, Korea University College of Medicine, 97 Guro-donggil, Seoul,

Guro-gu 152-703, Korea
}

patients with early-stage non-small cell lung cancer (NSCLC), when compared with open surgery $[8,9]$, more sufficient information regarding the oncologic efficacy of this procedure needs to accumulate to gain wide spread acceptance of this procedure $[5,10]$.

Nevertheless, the literature shows that in the hands of experienced VATS surgeons, a lobectomy is a safe operation that offers patients comparable or better complication rates, compared to that of the conventional lobectomy by thoracotomy [11]. Moreover, as VATS lobectomy techniques continue to improve by some pioneers in the field of VATS lobectomy, attempts to decrease the size of the working port, the diameter of thoracoscope and instruments, as well as the number of incision has gradually been made [12-15]. Recently, Borro and colleagues [15] reported the feasibility of VATS lobectomy with two ports and said that the 3rd port is not necessary for the majority of cases, despite the use of three ports by most of the surgeons.
( Biomed Central

(c) 2013 Kim et al.; licensee BioMed Central Ltd. This is an Open Access article distributed under the terms of the Creative Commons Attribution License (http://creativecommons.org/licenses/by/2.0), which permits unrestricted use, distribution, and reproduction in any medium, provided the original work is properly cited. 
Although the third port was already made at the beginning of the operation, we occasionally did not use this port during a VATS lobectomy procedure. This is because, on a usual case, the operator only used the working port, which was made at the operator's side, and the assistant therefore, used the thoracoscopic port. The 3rd port, which was made at the assistant side, was usually unnecessary during a VATS lobectomy with the exception of some unexpected situations. Therefore, the author (K.H.K) started to perform VATS lobectomy with only two working ports, without the 3rd port, since July 2010. In this study we evaluated the safety and feasibility of VATS lobectomy with two incisions.

\section{Methods}

Consecutive patients, who underwent major pulmonary resection (segmentectomy, lobectomy, bilobectomy, and pneumonectomy) through VATS using two incisions, from July 2010 to December 2011, in Korea Unversity Guro Hospital, were included in this study. This study was performed through a retrospective chart review. It was approved by the Korea University Guro Hospital Ethics Committee (KUGH12076) and the informed consent was waived.

As long as lesions were amenable to anatomic resection and patients were expected to be able to tolerate single-lung ventilation, as determined by preoperative pulmonary function tests, we performed a two-incision VATS lobectomy to various benign or malignant pulmonary diseases [10]. For benign lung diseases, VATS lobectomy was not attempted when preoperative computed tomography $(\mathrm{CT})$ findings revealed the following: a definite pleural calcification, tight calcification stuck to the pulmonary vessel, thoracic cage deformity, or decreased volume of ipsilateral lung, which all implied severely dense adhesion [10]. For malignant lung disease, absolute contraindications include a tumor of $6 \mathrm{~cm}$ or larger, invasive mediastinal tumor, and the inability to perform a complete resection with lobectomy, bilobectomy, or pneumonectomy. Relative contraindications include advanced disease or neoadjuvant chemo- or radiotherapy, endobronchial tumor requiring bronchoplasty, or lymph node affectation, which seriously hinders hilar dissection.

In our hospital, since VATS lobectomy launched in March 2006, two ports and a utility incision had been used without rib spreading. A $12 \mathrm{~mm}$ sized trocar, for the thoracoscope with $10 \mathrm{~mm}$ in size and 30 degree, was placed at the 7th or the 8th intercostal space in the midaxillary line, and a 3 to $5 \mathrm{~cm}$ sized utility incision was made at the 5th intercostal space in the anterior or the posterior axillary line. An additional $5 \mathrm{~mm}$ sized trocar was placed at the 5th or the 6th intercostal space in the anterior or the posterior axillary line. In this study, we apply a two-incision VATS lobectomy without this 3rd port at any lobe from the start (Figure 1). The vessels and bronchi of the target lobe were individually dissected. For patients with benign disease, we prefer to staple the pulmonary artery first, and then the vein, whenever possible, to prevent vein congestion. For patients with malignant disease, we prefer to staple the pulmonary vein first and then the artery, whenever possible, to prevent possible tumor seeding through the pulmonary vein, and complete mediastinal lymph node dissection was mandatory. During this procedure, in case of needing assistant's retraction of tissue, two instruments from the operator and one instrument from the assistant are usually introduced all together, through the working port. Further, we free to exchange the thoracoscope and the endostaplers from one incision to the other for the resection of hilar structures (Figure 2). All specimens were placed into an impermeable bag and removed through the utility incision, and a single chest tube is placed at the end of the surgery.

Variables, such as patient's age and sex, histology, type and duration of surgery, duration of chest tube, length of hospital stay, and postoperative complications and mortality were analyzed. In addition, for patients with cancer, clinical and pathologic TNM stage of cancer, and the number of dissected lymph node were studied, additionally.

Descriptive statistics were used to describe the patient's demographic characteristics and outcomes. Normally distributed continuous data were expressed as the mean \pm standard deviation. Categorical data were expressed as count and proportion. Student's t-test and the chi-square test or Fisher's exact test were used to compare continuous and categorical variables, respectively. SPSS (ver. 12; SPSS Inc., Chicago, IL, USA) for windows was used for statistical analysis.

\section{Results}

A total of 73, out of 108 (68\%) (male 47, female 26; mean age $61.2 \pm 12.00$ years old, range 19 85), who underwent major pulmonary resection (segmentectomy, lobectomy, bilobectomy, or pnemonectomy) through a consecutive VATS using two incisions from July 2010 to December 2011, were included in this study. Among the remaining 35 patients, five patients, who had undergone neoadjuvant chemotherapy $(\mathrm{n}=4)$ or concurrent chemoradiotherapy $(n=1)$, underwent a standard VATS lobectomy from the start, and they were excluded in this study. Therefore, 78 patients, out of 108 (72\%), who underwent major pulmonary resection have undergone a VATS lobectomy.

The preoperative diagnosis was benign lung disease in 8 patients (11\%) (3 pulmonary sequestration, 3 pulmonary tuberculosis, 1 emphysema, and 1 bronchogenic cyst) and malignant lung disease in 65 patients (89\%) (61 primary lung cancer, 4 metastatic lung cancer) (Table 1). Clinical 

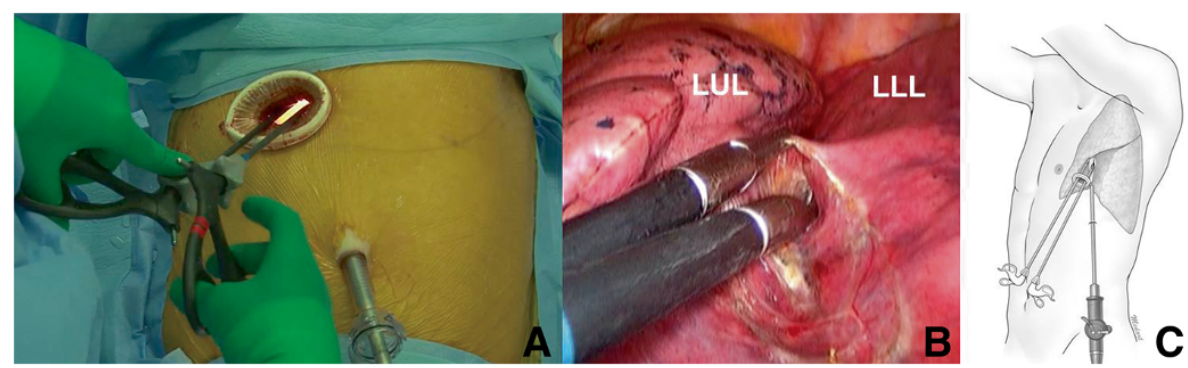

Figure 1 Two-incision video-assisted thoracoscopic (VATS) left lower lobectomy. (A) The operator always took place at the right side of the patient, a thoracoscopy port is located at the 7th intercostal space in the mid-axillary line, and a utility incision, $4 \mathrm{~cm}$ long, at the 5th intercostal space, in the operator side. (B) Dissection of major pulmonary fissure using $5 \mathrm{~mm}$ sized instruments through a utility incision. (C) Schematic illustration of a two-incision VATS left lower lobectomy.

stage of primary lung cancer $(\mathrm{n}=61)$ was $\mathrm{T} 1$ or T2N0M0 in 47 patients $(77 \%)$, T3N0M0 in $3(5 \%)$, and $\mathrm{N} 1(\mathrm{n}=9)$ or $\mathrm{N} 2(\mathrm{n}=2)$ in $11(18 \%)$. Two patients with N2 disease, one with $\mathrm{N} 1$, and one with T3 underwent preoperative adjuvant chemotherapy.

Lobectomy was performed in most patients $(n=67)$, and bilobectomy was performed in 3 patients, pneumonectomy in 1 , and segmentectomy in 2 . One patient underwent right middle lobectomy through same incision, 2 days after the right upper lobectomy, due to right middle lobe torsion.

Two patients (3\%) needed the third port during the surgery because of severe pleural adhesion (Table 2), and suffered from prolonged air leakage after the surgery (Table 3). Conversion to thoracotomy was performed in 5 patients (7\%) due to bleeding at pulmonary arterial branch $(\mathrm{n}=3)$, anthracofibrotic lymph nodes around pulmonary artery $(\mathrm{n}=1)$, and severe pleural adhesion $(\mathrm{n}=1)$. Two of these 3 patients with bleeding at the pulmonary artery, had undergone neoadjuvant chemotherapy. Two of these 5 patients suffered from atelectasis or prolonged air leakage after the surgery.

The mean time of the operation, in 66 patients who were completed by two-incision VATS lobectomy, was
$163.4 \pm 30.40$ minutes (range, 85 277). According to the site of lobectomy, the operation time of the upper lobectomy was longer than that of the middle or lower lobectomy $(173.6 \pm 32.51$ minutes vs $154.3 \pm 25.56, \mathrm{p}=0.010)$. Further, according to the period, the operation time of the first 33 cases was longer than the last 33 cases (171.3 \pm 532.25 minutes vs $152.5 \pm 32.72, \mathrm{p}=0.037)$. In 56 cases, which were completed by two-port VATS lobectomy for primary lung cancer, the total number of dissected lymph nodes per patient was $20.2 \pm 11.2$ (range, 6 52). The chest tube was removed on postoperative day $5.4 \pm 2.8$ (range, $3 \sim 15$ ), and there was no occurrence of major perioperative morbidity and mortality.

\section{Discussion}

Although major pulmonary resection using VATS has gained popularity, due to its potential benefits, which includes faster patient recovery, fewer complications, and shorter hospital stay without compromising the oncologic aspects of the operation, the definition of VATS lobectomy has not been established until now [5]. Various factors regulate the definition of VATS lobectomy, for example: use of rib spreading, variety of the devices, length and location of the utility incision, number of thoracotomy ports,
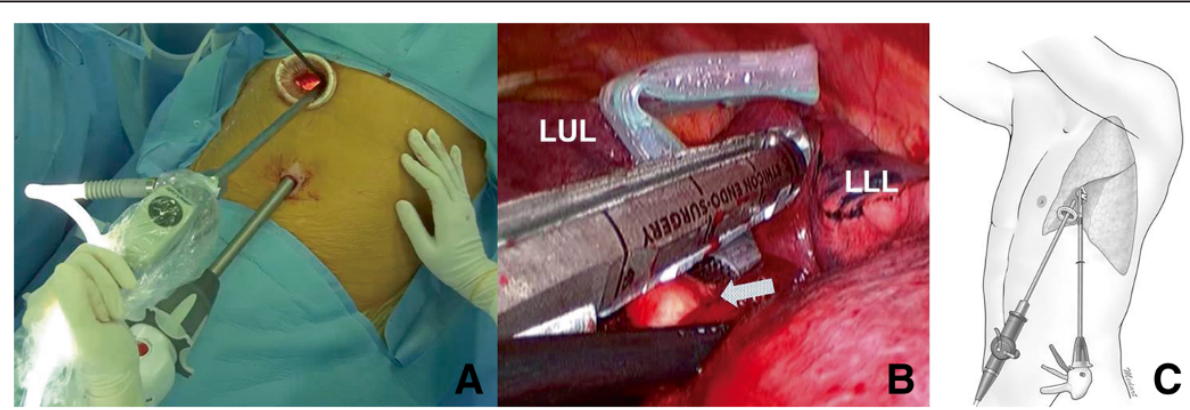

Figure 2 Division pulmonary arterial branches to left lower lobe (A), (B), (C). Exchanging the thoracoscope and the endostapler from one incision to the other during the two-incision video-assisted thoracoscopic left lower lobectomy. An arrow indicates pulmonary arterial branches to left lower lobe. 
Table 1 Patients' characteristics

\begin{tabular}{|c|c|c|}
\hline \multicolumn{2}{|l|}{ Characteristics } & \multirow{2}{*}{$\frac{\text { No. (\%) }}{65(89)}$} \\
\hline Histology & Malignancy & \\
\hline & Primary & $61(84)$ \\
\hline & Adenocarcinoma & $35(48)$ \\
\hline & Squamous cell carcinoma & $18(25)$ \\
\hline & Others & $8(11)$ \\
\hline & Metastasis & $4(6)$ \\
\hline & $\begin{array}{l}\text { Recurrent lung cancer } \\
\text { (adenocarcinoma) }\end{array}$ & $2(3)$ \\
\hline & Rectal cancer (Adenocarcinoma) & $2(3)$ \\
\hline & Benign & $8(11)$ \\
\hline & Tuberculosis & $3(4)$ \\
\hline & Bronchiectasis & $3(4)$ \\
\hline & Pulmonary sequestration & $1(1)$ \\
\hline & Bronchogenic cyst & $1(1)$ \\
\hline \multirow{8}{*}{$\begin{array}{l}\text { Type of surgery } \\
(n=74)\end{array}$} & Segmentectomy & $2(3)$ \\
\hline & Right upper lobectomy & $20(27)$ \\
\hline & Right middle lobectomy & $5(7)$ \\
\hline & Right lower lobectomy & $18(24)$ \\
\hline & Left upper lobectomy & $11(15)$ \\
\hline & Left lower lobectomy & $14(19)$ \\
\hline & Bilobectomy (right middle \& lower) & $3(4)$ \\
\hline & Pneumonectomy (left) & $1(3)$ \\
\hline
\end{tabular}

scope of the light source or monitoring, how to treat vessels, how to dissect lymph node, and so on $[16,17]$. At the present time, most thoracic surgeons agree to define VATS lobectomy as a procedure with one 4 to $8 \mathrm{~cm}$ sized utility port incision and one to three 0.5 to $1 \mathrm{~cm}$ sized port incisions, while avoiding rib spreading, and with the use of a camera for viewing purposes $[5,10,18]$.

In our hospital, since VATS lobectomy launched in March 2006, two ports and a utility incision had been
Table 3 Postoperative complications

\begin{tabular}{ll}
\hline & No (\%) \\
\hline Prolonged air leak (>5 days) & $4(5.5)$ \\
Atelectasis & $2(2.7)$ \\
Pneumonia & $1(1.4)$ \\
Reoperation & $1(1.4)$ \\
Atrial fibrillation & $1(1.4)$ \\
\hline
\end{tabular}

used without rib spreading. As mentioned before, our method for port placement enabled the operator to only use the utility incision, and the assistant to only use the $5 \mathrm{~mm}$ port, most of the time during the operation.

While we had performed more than 120 VATS lobectomies, the need for the third port gradually has begun to decrease, with the build-up of the surgeon's experience. In addition, around the same time, Borro and colleagues [15] published a paper on two-incision approach for VATS lobectomy. Therefore, we considered the twoincision VATS lobectomy feasible, and started to perform this procedure without the third port. To make the anatomical resection through only two incisions, it is essential to learn the technical tips. Firstly, the thoracoscope and the endostaplers are exchanged from one incision to the other for the resection of hilar structure, according to the lobectomy site [15]. Secondly, in case of the need for retraction of some structures, such as lung, bronchus, or vessel, during hilar dissection, and natural gravity could be used by rotating the operating table, or $5 \mathrm{~mm}$ sized blunt tip dissector (Ethicon Endo Surgery, LLC, 475 Calle C Guyando, PR 00969, USA) taken by the assistant, which could be introduced through the utility port.

When the 3rd port or conversion to thoracotomy was needed, we did it without hesitation during the surgery. Nevertheless, only in 2 patients, the 3rd port needed due to severe pleural adhesion, and in 5 patients $(6.8 \%)$, conversion to thoracotomy was needed, mostly due to major

Table 2 Characteristics of patients with conversion to 3 ports or thoracotomy during two ports VATS lobectomy

\begin{tabular}{|c|c|c|c|c|c|c|}
\hline Sex & Age & Diagnosis & $\begin{array}{l}\text { Neoadjuvant } \\
\text { chemotherapy }\end{array}$ & Cause of conversion & Type of surgery & Complications \\
\hline \multicolumn{7}{|c|}{ Conversion to three ports $(n=2,3.1 \%)$} \\
\hline Male & 69 & Metastatic lung cancer & Yes & Severe pleural adhesion & Right lower lobectomy & Prolonged air leak \\
\hline Female & 60 & Primary lung cancer & No & Severe pleural adhesion & Left upper lobectomy & Prolonged air leak \\
\hline \multicolumn{7}{|c|}{ Conversion to thoracotomy $(n=5,6.8 \%)$} \\
\hline Male & 71 & Primary lung cancer & Yes & Bleeding at pulmonary arterial branch & Right lower lobectomy & No \\
\hline Male & 74 & Primary lung cancer & No & $\begin{array}{l}\text { Calcified lymph node around pulmonary } \\
\text { arterial branch }\end{array}$ & Right lower lobectomy & No \\
\hline Male & 71 & Primary lung cancer & Yes & Bleeding at pulmonary arterial branch & Right upper lobectomy & Atelectasis \\
\hline Male & 59 & Primary lung cancer & Yes & Bleeding at pulmonary arterial branch & Left upper lobectomy & No \\
\hline Male & 71 & Primary lung cancer & No & Severe pleural adhesion & Right lower lobectomy & Prolonged air leak \\
\hline
\end{tabular}


vessel bleeding. The rate of conversion to thoracotomy in this study is comparable with the results of the Borro's report [15] of two-incision VATS lobectomy (10\%) and the standard VATS lobectomy $(1.6 \%$ 11.8\%) [17].

While controversy still exists concerning the oncologic effectiveness of VATS lobectomy, especially its efficacy in the mediastinal lymph node dissection (MLND), research to date has confirmed its feasibility and safety, as well as equivalent outcomes as compared to conventional open thoracotomy [19] Complete MLND has been the principle of our hospital, during VATS lobectomy in patients with primary lung cancer. When we began to perform the two-incision VATS lobectomy, we focused to keep this principle thoroughly. Therefore, since the first case of this procedure, the number of dissected lymph node has not been different from the data of our previous three-port VATS lobectomy or lobectomy through standard thoracotomy $(20.2 \pm 11.2$ in this study, $22.1 \pm 11.6$ in our previous data including three-port VATS lobectomy or lobectomy through standard thoracotomy [20]). Our number of dissected lymph node is much higher than that of the Borro's report $(9.2 \pm 5.4)$ [15] and it is comparable with the other group's data of standard VATS lobectomy (10 23) [5,21-23].

The authors performed a two-incision VATS segmentectomy in 2 patients. We have considered patients with a tumor smaller than $2 \mathrm{~cm}$ in diameter diagnosed or suspected as a clinical T1NOM0 carcinoma in the lung periphery based on a CT scan as candidates for the segmentectomy as an alternative anatomical resection $[24,25]$. They had no perioperative and postoperative problems, but we should have enough of these cases in order to compare with the conventional standard approach.

In this study, 2 patients with lung cancer who underwent neoadjuvant chemotherapy were included, although they are currently considered as contraindication for VATS lobectomy. Recently, as VATS lobectomy techniques continue to improve, expanding the indications for VATS, as well as for complex procedures, such as segmentectomy or sleeve resection, is currently a more pressing issue for treating advanced lung cancer [26]. Therefore, in our hospital, when it has seemed to be feasible to perform a two incision VATS lobectomy after careful thoracoscopic examination even in lung cancer patients with neoadjuvant chemotherapy, we have tried to perform this procedure.

The operation time in this study is similar to our previous data of standard VATS lobectomy $(163.4 \pm 30.40$ vs. $146.8 \pm 26.30$ minutes, $p=0.238$ ), and it is not different with Borro' result (168 minutes) [15]. However, these results appeared to be longer than that of the standard VATS lobectomy in other series (118 130 minutes) $[16,17]$. When we analyzed this, according to the site of lobectomy, the operation time of upper lobectomy was longer than that of middle or lower lobectomy. Further, according to the period, the operation time of the first 33 cases was longer than the last 33 cases. Moreover, the operation time of the last 33 cases is not different from our previous data of standard VATS lobectomy $(p=0.526)$.

Therefore, we thought that as more procedures are performed and the learning curve of the surgeon improves with this two ports procedure, the operation time will become shortened and will therefore, have similar results as those recorded for the three ports approach. Two ports VATS lobectomy is not a new technique. It has been known that few surgeons have already carried out this procedure [15,27-29]. D'Amico's group reported that two incisions were used in the majority of patients, among the 500 cases [27], and Borro and colleagures firstly used the terminology of two-incision VATS lobectomy [15]. The performance of two, three or four incisions in VATS lobectomy seems to have no influence on the short-term postoperative outcomes. Two ports VATS lobectomy is a consequence of greater skills acquired with experience [15], and could be a process of less minimally invasive procedure to a single port or natural orifice transluminal endoscopic surgery in the thoracic surgical field of the future. Therefore, as the accumulation of surgical skills and experience, we don't need to insist on using the 3rd port in VATS lobectomy, although the elimination of the third port is not helpful to the patient in the operative outcomes.

\section{Conclusions}

Two-incision VATS lobectomy is applicable in selected cases, and may obtain similar results with the conventional VATS lobectomy, given a certain period of learning curve.

\section{Abbreviations}

CT: Computed tomography; NSCLC: Non-small cell lung cancer; VATS: Videoassisted thoracoscopic surgery.

\section{Competing interests}

The authors declare that they have no competing interests.

\section{Authors' contributions}

HKK contributed to surgical procedure, reviewing data and drafting the article. HKS contributed to surgical procedure and analyzing data. HJL contributed to surgical procedure and collecting data. YHC contributed to reviewing data. All authors read and approved the final manuscript.

\section{Acknowledgements}

This research was supported by Basic Science Research Program through the National Research Foundation of Korea (NRF) funded by the Ministry of Education, Science and Technology(20120003904).

Received: 31 December 2012 Accepted: 12 April 2013

Published: 15 April 2013

\section{References}

1. Hermansson U, Konstantinov IE, Arén C: Video-assisted thoracic surgery (VATS) lobectomy: the initial Swedish experience. Semin Thorac Cardiovasc Surg 1998, 10:285-290. 
2. McKenna RJ Jr, Fischel RJ, Wolf R, Wurnig P: Video-assisted thoracic surgery (VATS) lobectomy for bronchogenic carcinoma. Semin Thorac Cardiovasc Surg 1998, 10:321-325.

3. McKenna RJ Jr, Houck W, Fuller CB: Video-assisted thoracic surgery lobectomy: experience with 1,100 cases. Ann Thorac Surg 2006, 81:421-425. discussion 425-426.

4. Whitson BA, Andrade RS, Boettcher A, Bardales R, Kratzke RA, Dahlberg PS, Maddaus MA: Video-assisted thoracoscopic surgery is more favorable than thoracotomy for resection of clinical stage I non-small cell lung cancer. Ann Thorac Surg 2007, 83:1965-1970.

5. Scott WJ, Allen MS, Darling G, Meyers B, Decker PA, Putnam JB, McKenna RW Landrenau RJ, Jones DR, Inculet RI, Malthaner RA: Video-assisted thoracic surgery versus open lobectomy for lung cancer: a secondary analysis of data from the American College of Surgeons Oncology Group Z0030 randomized clinical trial. J Thorac Cardiovasc Surg 2010, 139:976-981. discussion 981-983.

6. Yamashita Jl, Kurusu Y, Fujino N, Saisyoji T, Ogawa M: Detection of circulating tumor cells in patients with non-small cell lung cancer undergoing lobectomy by video-assisted thoracic surgery: a potentia hazard for intraoperative hematogenous tumor cell dissemination. J Thorac Cardiovasc Surg 2000, 119:899-905.

7. Kawachi R, Tsukada H, Nakazato Y, Takei H, Koshi-ishi Y, Goya T: Morbidity in video-assisted thoracoscopic lobectomy for clinical stage I non-small cell lung cancer: is VATS lobectomy really safe? Thorac Cardiovasc Surg 2009, 57:156-159.

8. Yan TD, Black D, Bannon PG, McCaughan BC: Systematic review and metaanalysis of randomized and nonrandomized trials on safety and efficacy of video-assisted thoracic surgery lobectomy for early-stage non-small -cell lung cancer. J Clin Oncol 2009, 27:2553-2562.

9. Cao C, Manganas C, Ang SC, Yan TD: A meta-analysis of unmatched and matched patients comparing video-assisted thoracoscopic lobectomy and conventional open lobectomy. Ann Cardiothorac Surg 2012, 1:16-23.

10. Kim K, Kim HK, Park JS, Chang SW, Choi YS, Kim J, Shim YM: Video-assisted thoracic surgery lobectomy: single institutional experience with 704 cases. Ann Thorac Surg 2010, 89:\$2118-S2122.

11. Mahtabifard A, McKenna RJ Jr: Video-assisted thoracic surgery for wedge resection, lobectomy, and pneumonectomy. In General thoracic surgery. 7th edition. Edited by Shields TW, LoCicero J, Reed CE, Feins RH. Philadelphia, PA: Lippincott Williams \& Wilkins; 2009:523-531.

12. Shigemura N, Akashi A, Nakagiri T, Ohta M, Matsuda H: Complete versus assisted thoracoscopic approach: a prospective randomized trial comparing a variety of video-assisted thoracoscopic lobectomy techniques. Surg Endosc 2004, 18:1492-1497.

13. He J, Shao W, Cao C, Yan T, Wang D, Xiong XG, Yin W, Xu X, Chen H, Qiu Y, Zhong B: Long-term outcome and cost-effectiveness of complete versus assisted video-assisted thoracic surgery for non-small cell lung cancer. J Surg Oncol 2011, 104:162-168.

14. Göttgens KW, Siebenga J, Belgers EH, van Huijstee PJ, Bollen EC: Early removal of the chest tube after complete video-assisted thoracoscopic lobectomies. Eur J Cardiothorac Surg 2011, 39:575-578.

15. Borro JM, Gonzalez D, Paradela M, de la Torre M, Fernandez R, Delgado M, Garcia J, Fieira E: The two-incision approach for video-assisted thoracoscopic lobectomy: an initial experience. Eur J Cardiothorac Surg 2011, 39:120-126.

16. Rocco G, Internullo E, Cassivi SD, Van Raemdonck D, Ferguson MK: The variability of practice in minimally invasive thoracic surgery for pulmonary resections. Thorac Surg Clin 2008, 18:235-247.

17. Yamashita Y, Harada H, Misumi K: Video-assisted thoracic surgery lobectomy for lung cancer: the point at issue. Gen Thorac Cardiovasc Surg 2011, 59:164-168.

18. Swanson SJ, Herndon JE 2nd, D'Amico TA, Demmy TL, McKenna RJ Jr, Green MR, Sugarbaker DJ: Video-assisted thoracic surgery lobectomy: report of CALGB 39802-a prospective, multi-institution feasibility study. J Clin Oncol 2007, 25:4993-4997.

19. Wang $H$, D'Amico TA: Efficacy of mediastinal lymph node dissection during thoracoscopic lobectomy. Ann Cardiothorac Surg 2012, 1:27-32

20. Kim S, Kim HK, Kang DY, Jeong JM, Choi YH: Intra-operative sentinel lymph node identification using a novel receptor-binding agent (technetium-99m neomannosyl human serum albumin, 99mTc-MSA) in stage I non-small cell lung cancer. Eur J Cardiothorac Surg 2010, 37:1450-1456.
21. Sugi K, Kaneda Y, Esato K: Video-assisted thoracoscopic lobectomy achieves a satisfactory long-term prognosis in patients with clinical stage IA lung cancer. World J Surg 2000, 24:27-30. discussion 30-31.

22. Watanabe A, Koyanagi T, Obama T, Ohsawa H, Mawatari T, Takahashi N, Ichimiya Y, Abe T: Assessment of node dissection for clinical stage I primary lung cancer by VATS. Eur J Cardiothorac Surg 2005, 27:745-752.

23. Amer K, Khan AZ, Singh N, Addis B, Jogai S, Harden S, Peebles C, Brown I: Video-assisted thoracic surgery systematic mediastinal nodal dissection and stage migration: impact on clinical pathway. Eur J Cardiothorac Surg 2011, 40:1474-1481

24. Wang BY, Liu CC, Shih CS: Short-term results of thoracoscopic lobectomy and segmentectomy for lung cancer in koo foundation sun yat-sen cancer center. J Thorac Dis 2010, 2:64-70.

25. Yoshida J: Management of the peripheral small ground-glass opacities. Thorac Surg Clin 2007, 17:191-201. viii.

26. Ikeda N, Saji H, Hagiwara M, Ohira T, Usuda J, Kajiwara N: Recent advances in video-assisted thoracoscopic surgery for lung cancer. Asian J Endosc surg 2013, 6:9-13.

27. Onaitis MW, Petersen RP, Balderson SS, Toloza E, Burfeind WR, Harpole DH Jr, D'Amico TA: Thoracoscopic lobectomy is a safe and versatile procedure: experience with 500 consecutive patients. Ann Surg 2006, 244:420-425

28. Yim AP, Izzat MB, Liu HP, Ma CC: Thoracoscopic major lung resections: an Asian perspective. Semin Thorac Cardiovasc Surg 1998, 10:326-331.

29. Kaseda S, Aoki T, Hangai N: Video-assisted thoracic surgery (VATS) lobectomy: the Japanese experience. Semin Thorac Cardiovasc Surg 1998, 10:300-304

doi:10.1186/1749-8090-8-88

Cite this article as: Kim et al:: The feasibility of a Two-incision videoassisted thoracoscopic lobectomy. Journal of Cardiothoracic Surgery 2013 8:88.

\section{Submit your next manuscript to BioMed Central and take full advantage of:}

- Convenient online submission

- Thorough peer review

- No space constraints or color figure charges

- Immediate publication on acceptance

- Inclusion in PubMed, CAS, Scopus and Google Scholar

- Research which is freely available for redistribution

Submit your manuscript at www.biomedcentral.com/submit
C) Biomed Central 